\title{
ENERGETIC ADVANTAGES OF SLIGHT DROPS IN BODY TEMPERATURE IN LITTLE BROWN BATS, MYOTIS LUCIFUGUS
}

\author{
EUGENE H. STUdieR \\ Department of Biology, University of Michigan-Flint, Flint, MI 48503, U.S.A.
}

(Receiled 12 May 1981)

\begin{abstract}
At constant ambient temperatures $\left(T_{a}\right)$ below their thermal neutral zone (TNZ), little brown bats, Myotis lucifugus, maintain a wide range of steady-state body temperatures $\left(T_{h}\right)$.

2. The relationship between oxygen consumption and $T_{b}-T_{a}$ differential at constant $T_{a}$ s below the TNZ is curvilinear.

3. Small drops in $T_{b}$ from high $T_{b}$ levels result in significantly greater energy savings than subsequent $T_{b}$ reductions of equal increments.
\end{abstract}

\section{INTRODUCTION}

Deep body temperature $\left(T_{b}\right)$ and oxygen consumption (OC) as functions of ambient temperature $\left(T_{a}\right)$ have been determined for a wide variety of mammals. Assuming that the organisms under consideration do not significantly utilize anaerobic energy producing metabolic pathways and $T_{b}$ is constant during the period of measurement, the rate of $O C$ is directly related, with little error, to metabolic heat production. Possible interrelationships between $T_{b}, \mathrm{OC}$, and $T_{a}$ have often been discussed and debated (Scholander et al.. 1950; Kleiber, 1961; King, 1964; Tucker, 1965; Porter \& Gates, 1969; McNab, 1970; Strunk, 1971; Kleiber, 1972; Calder, 1972; Calder \& King, 1972; Strunk et al., 1973; McNab, 1980). Of particular intercst is the relationship of $\mathrm{OC}$ and the $T_{b}-T_{a}$ differential $\left(T_{b}-T_{a}\right)$ in endotherms at $T_{a}$ s below the thermal neutral zone (TNZ). In mammals in which steady-state $T_{b}$ is constant and independent of $T_{a}$, i.e. in homeothermic endotherms, $T_{b}-T_{a}$ differential can be obtained only by varying $T_{a}$. It is, therefore, impossible to analyze the relation of $\mathrm{OC}$ to $T_{b}-T_{a}$ at constant $T_{a}$ in such species. Among heterothermic endotherms, however, some data are available (Studier \& O'Farrell, 1972, 1976) for $O C$ at a wide range of steady-state $T_{b}$ s at constant $T_{a}$. This paper reports the relationships between $\mathrm{OC}$ and $T_{b}-T_{a}$ at constant $T_{a}$ s below the TNZ in a heterothermic endotherm, the little brown bat, Myotis lucifugus, and comments on the energetic advantages of this thermoregulatory strategy.

\section{MATERIALS AND METHODS}

Data analyzed for the present study are taken from Studier \& O'Farrell (1972). Details of materials and methods used appear in that paper and will be summarized here. Adult, female little brown bats of varying reproductive conditions (pregnant, lactating, post-lactating) collected throughout the summer from a maternity colony were studied. All laboratory studies were performed on the day of capture. Steady-state OC and $T_{b}$ were recorded at $T_{a} \mathrm{~s}$ of $16-40^{\circ} \mathrm{C}$ at $4^{\circ} \mathrm{C}$ intervals. Laboratory controlled $T_{a} \mathrm{~s}$ were programmed to coincide with $T_{a} \mathrm{~s}$ in the natural roost.

\section{RESULTS AND DISCUSSIONS}

Steady-state $T_{b} s$ of little brown bats at various controlled $T_{a} \mathrm{~s}$ (shown in Fig. 1) indicate the heterothermic pattern of thermoregulation exhibited by these bats when tested on the day of capture. Much of the variability in level of regulated $T_{b}$ is a function of stage of pregnancy, stage of reproductive cycle, etc. (Studier \& O'Farrell, 1972).

Data on OC and $T_{b}-T_{a}$ at various controlled $T_{a} \mathrm{~s}$ from $16-32^{\circ} \mathrm{C}$ were analyzed by both stepwise polynomial regression and by least squares regression analysis of eleven possible power, root, and reciprocal transformations of both $\mathrm{OC}$ and $T_{b}-T_{a}$ together and independently to determine the best statistical descriptions of the relationships between these variables. Regression coefficients for the independent variable $\left(T_{b}-T_{a}\right)$ as a squared term or squared transformation were invariably significant, except at a $T_{a}$ of $32^{\circ} \mathrm{C}$. Based on comparing coefficients of determination $\left(r^{2}\right)$ for maximal values, the best uniform regression analysis, except at $32^{\circ} \mathrm{C}$, were curvilinear equations of the form $y-b x^{2}+a$, where $y$ is OC in cc/g per hr and $x$ is $T_{b}-T_{a}$ in ${ }^{\circ}$. Equations are given in Table 1 and illustrated in Fig. 2. The relationship of $O C$ to $T_{b}-T_{a}$ becomes progressively less curved as $T_{a}$ rises until at a $T_{a}$ of $32^{\circ} \mathrm{C}$, which is the thermal neutral temperature for this species (Stones \& Wiebers, 1965), the relationship is linear. Since thermal conductance (McNab, 1980) is represented by the slopes of the lines in Fig. 2, at $T_{a}$ s below the $\mathrm{TNZ}$, thermal conductance is not a constant. Linear regression analysis of these variables (OC and $T_{b}-T_{a}$ ) will, therefore, underestimate actual thermal conductance when $T_{b}-T_{a}$ is large and overestimate thermal conductance when $T_{b}-T_{a}$ is small. As stated earlier, in homeothermic endotherms, the only method of obtaining $T_{b}-T_{a}$ is by modifying $T_{a}$. For such species, themal conductance is characteristically estimated by analyzing the slope of the relationship of OC to $T_{a}$ at $T_{a}$ s below the TNZ. Since $T_{b}$ is constant in such species, the abscissa is related to $T_{b}-T_{a}$ and resultant figures show a negative slope since $T_{b}-T_{a}$ decreases as $T_{a}$ rises. Such graphic representations are, 


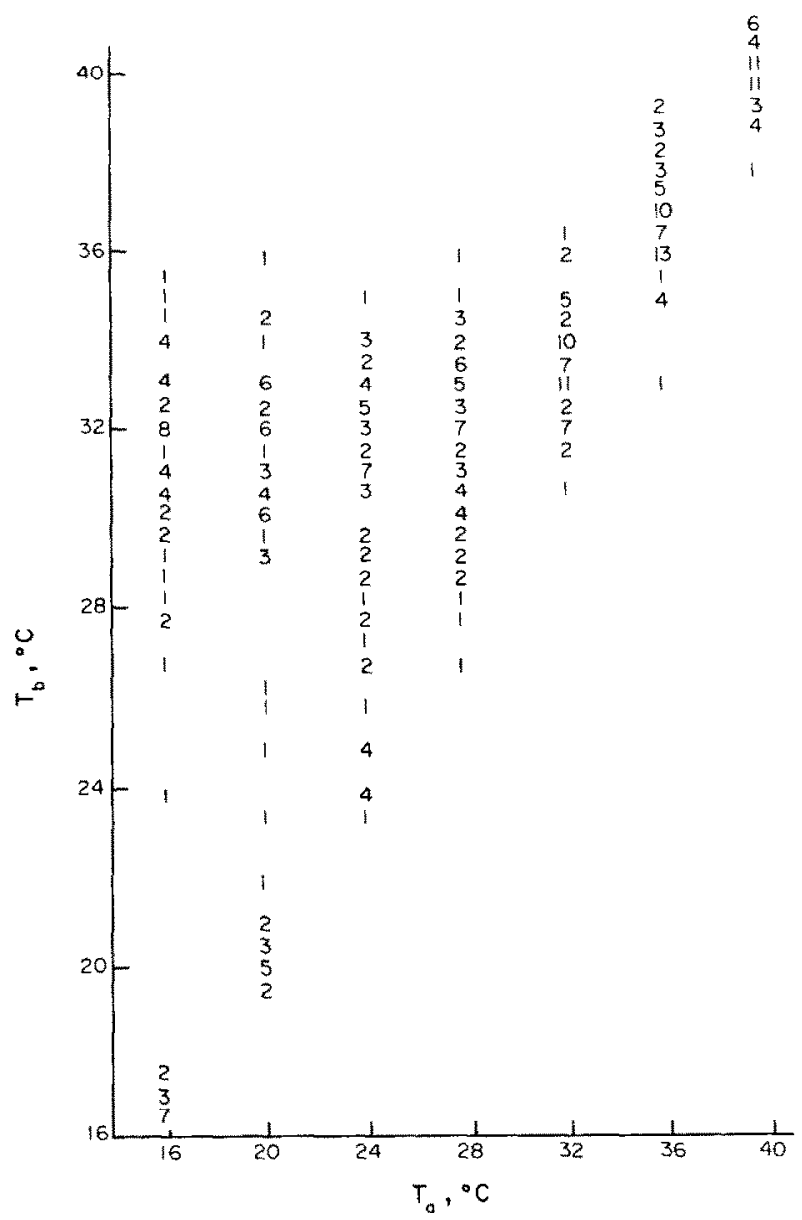

Fig. 1. Steady-state body temperatures $\left(T_{b}\right)$ of adult female Myotis lucifugus of varying reproductive condition at constant ambient temperatures $\left(T_{a}\right)$. Numbers indicate the number of data points at that position.

therefore, inverted left to right in comparison to Fig. 2. Inspection of some published figures depicting $O C$ as a function of $T_{a}$ in homeothermic endotherms

Table 1. Reduced statistical data for the relationship of oxygen consumption $(y$, in ce/g per hr) to body temperature to ambient temperature differential $\left(x\right.$, in $\left.{ }^{\circ} \mathrm{C}\right)$ at various ambient temperatures $\left(T_{a}\right)$ in Myotis lucifugus. Regression coefficients are for equations of the form $y=b x^{2}+a . P<0.0005$ in all cases. Values in parentheses are standard errors.

\begin{tabular}{|c|c|c|c|c|c|}
\hline \multirow[b]{2}{*}{$T_{a}(\mathrm{C})$} & \multicolumn{2}{|c|}{ Regression coefficients } & \multirow[b]{2}{*}{$F$} & \multirow[b]{2}{*}{ d.f. } & \multirow[b]{2}{*}{$r^{2}$} \\
\hline & $b$ & $a$ & & & \\
\hline 16 & $\begin{array}{c}0.0192 \\
(0.0013)\end{array}$ & $\begin{array}{c}0.268 \\
(0.154)\end{array}$ & 203.4 & 1,29 & 0.875 \\
\hline 20 & $\begin{array}{c}0.0194 \\
(0.0014)\end{array}$ & $\begin{array}{c}0.149 \\
(0.120)\end{array}$ & 182.8 & 1,23 & 0.888 \\
\hline 24 & $\begin{array}{c}0.0263 \\
(0.0020)\end{array}$ & $\begin{array}{c}0.558 \\
(0.077)\end{array}$ & 166.8 & 1,33 & 0.835 \\
\hline 28 & $\begin{array}{c}0.0430 \\
(0.0062)\end{array}$ & $\begin{array}{c}0.480 \\
(0.096)\end{array}$ & 48.6 & 1,29 & 0.627 \\
\hline $32 *$ & $\begin{array}{c}0.441 \\
(0.081)\end{array}$ & $\begin{array}{c}0.271 \\
(0.158)\end{array}$ & 29,4 & 1,32 & 0.487 \\
\hline
\end{tabular}

* Regression coefficients are for the linear equation: $y=b x+a$. shows relationships which appear to be curvilinear although they are often analyzed in rectilinear fashion (e.g. Banholzer, 1976; Grant \& Dawson, 1978; Kamau et al., 1979; Degabriele \& Dawson, 1979; Rübsamen \& Kettembeil, 1980). The rectilinearity of this relationship has been questioned previously (Tracy, 1972). Furthermore, when thermal conductance is calculated on individual measurements of $T_{b}$ and $\mathrm{OC}$, it is apparent for many species that thermal conductance is not constant (McNab, 1980). Since methods are available for curvilinear (polynomial) regression analysis, such analysis should be performed to determine the best descriptive statistics of data such as $\mathrm{OC}$ as a function of $T_{a}$ in homeothermic endotherms. Such analysis would yield more accurate estimates of minimal standard metabolism and thermal neutral temperature (Studier et al., 1975).

The curvilinearity of the relationship of $O C$ to $T_{n}-T_{a}$ at constant $T_{a} \mathrm{~s}$ in $M$. lucifugus (Fig. 2) would not appear to be related to changes in the bats' physical environment but probably reflects some animalregulated property. Possibilities include animal regulated differences in metabolic heat production and/or in heat flow through changes in conductivities of the shell (King \& Farner, 1961) or in peripheral blood flow, etc. The relatively linear, upper portions of the $\mathrm{OC}$ to $T_{b}-T_{a}$ relations (Fig. 2) may well be parallel 


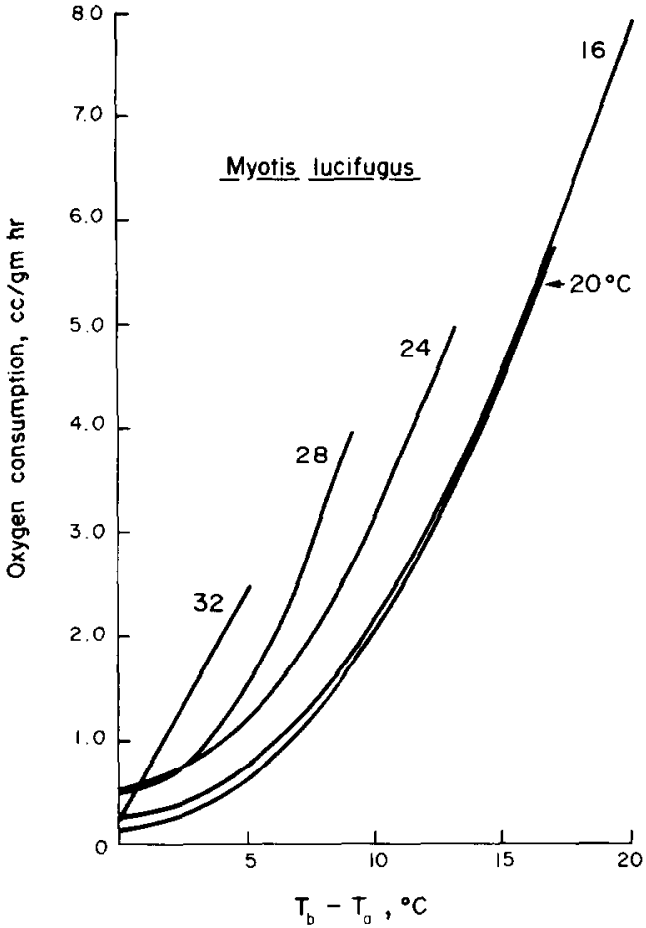

Fig. 2. Regression equations at various ambient temperatures for the relationship of oxygen consumption to body temperature to ambient temperature differential $\left(T_{b}-T_{a}\right)$ in Myotis lucifugus.

and indicate uniform energetic responses at various $T_{a} s$ when $T_{b}-T_{a}$ differential exceed a critical level. The lowering of $r^{2}$ values as $T_{a}$ increases indicates that $T_{b}-T_{a}$ differential explains progressively less of the variability in $\mathrm{OC}$.

While a statistically significant rectilinear relationship exists between $\mathrm{OC}$ and $T_{b}-T_{a}$ at all $T_{a}$ s analyzed, the relationship is best described by a curvilinear equation except at a $T_{a}$ of $32^{\circ} \mathrm{C}$. Use of a rectilinear equation predicts equal reductions in $\mathrm{OC}$ for any incremental reduction in $T_{b}$ whereas the curvilinear equations show larger reductions in $\mathrm{OC}$ when $T_{b}$ is reduced in equal increments from a high set point. As an example, at a $T_{a}$ of $20^{\circ} \mathrm{C}$ a drop in $T_{b}$ from $37^{\circ} \mathrm{C}$ $(5.76 \mathrm{cc} / \mathrm{g}$ per $\mathrm{hr})$ to $33^{\circ} \mathrm{C}(3.43 \mathrm{cc} / \mathrm{g}$ per hr) results in a reduction of $\mathrm{OC}$ of $2.33 \mathrm{cc} / \mathrm{g}$ per hr. Using $4.8 \mathrm{cal} / \mathrm{cc}$ of oxygen as an energy equivalent, this is a savings of $11.2 \mathrm{cal} / \mathrm{g}$ per hr. A further drop in $T_{b}$ from $33^{\circ} \mathrm{C}$ to $29^{\circ} \mathrm{C}(1.72 \mathrm{cc} / \mathrm{g}$ per $\mathrm{hr})$ results in a considerably reduced energy savings of only $8.2 \mathrm{cal} / \mathrm{g}$ per $\mathrm{hr}$.

It is also useful to consider encrgy requirements for raising $T_{b}$. At a $T_{a}$ of $16^{\circ} \mathrm{C}$, minimum OC in $M$. lucifugus, when $T_{b}-T_{a}=0$, is $0.268 \mathrm{cc} / \mathrm{g}$ per hr. A doubling of $\mathrm{OC}$, to $0.536 \mathrm{cc} / \mathrm{g}$ per hr, yields a $T_{b}-T_{a}$ of $3.7^{\circ} \mathrm{C}$; a tripling of $\mathrm{OC}$ yields a $T_{b}-T_{a}$ of $5.3^{\circ} \mathrm{C}$; and, a quadrupling of minimal $\mathrm{OC}$ gives a $T_{b}-T_{a}$ of $6.5^{\circ} \mathrm{C}$. From this perspective, the curvilincarity of the relation of $\mathrm{OC}$ to $T_{b}-T_{a}$ supports the hypotheses that homeothermy evolved gradually (Dawson et al., 1979) or in stepwise intervals (Crompton et al., 1978) rather than as a single major jump (Dawson \& Hulbert, 1970), since the intermediate set points for controlled $T_{b}$ require disproportionately less energy than a very high $T_{b}$ set point.

Acknowledgements-I thank Drs Bruce Wunder and William A. Calder for many useful comments on an earlier version of this manuscript and Dr Richard W. Dapson for his criticisms throughout the development of this manuscript.

\section{REFERENCES}

BANHOLZER U. (1976) Water balance, metabolism, and heart rate in the fennec. Die Naturwissenschaften 63, 1-2.

Calder W. A. (1972) Heat loss from small birds: analogy with Ohm's Law and a re-examination of the "Newtonian model". Comp. Biochem. Physiol. 43A, 13-20.

Calder W. A. \& KING J. R. (1972) Body weight and the energetics of temperature regulation: a re-examination. J. exp. Biol. 56, 775-780.

Crompton A. W., Taylor C. R. \& Jagger J. A. (1978) Evolution of homeothermy in mammals. Nature $\mathbf{2 7 2}$, 333-336.

Dawson T. J. \& Hulbert A. J. (1970) Standard metabolism, body temperature, and surface areas of Australian marsupials. Am. J. Physiol, 218, 1233-1238.

Dawson T. J., Grani T. R. \& Fanning D. (1979) Standard metabolism of monotremes and the evolution of homeothermy. Aust. J. Zool. 27, 511-515.

DEGABRIELE R. \& DAwSON T. J. (1979) Metabolism and heat balance in an arboreal marsupial, the koala (Phascolarctos cinereus). J. comp. Physiol. 134, 293-301.

Grant T. R. \& Dawson T. J. (1978) Temperature regulation in the platypus, Ornithorhynchus anatinus: production and loss of metabolic heat in air and water. Physiol. Zool. 51, 315-332.

Kamau J. M. Z., Johansen K. \& Maloiy G. M. O. (1979) Thermoregulation and standard metabolism of the slender mongoose (Herpestes sanguineus). Physiol. Zool. 52, 594-602.

KING J. R. (1964) Oxygen consumption and body temperature in relation to ambient temperature in the whitecrowned sparrow. Comp. Biochem. Physiol. 12, 13-24.

KING J. R. \& FARNER D. S. (1961) Energy metabolism, thermoregulation, and body temperature. In Biology and Comparatire Physiology of Birds (Edited by Marshall A. J.) Vol. 2, pp. 215-288. Academic Press, London.

KLEIBER M. (1961) The Fire of Life. Wiley, New York.

Kleiber M. (1972) A new Newton's Law of Cooling? Science 178, 1283-1285.

MCNAB B. K. (1970) Body weight and the energetics of temperature regulation. J. exp. Biol. 53, 329-348.

MCNAB B. K. (1980) On estimating thermal conductance in endotherms. Physiol. Zool. 53, 145-156.

Porter W. P. \& Gates D. M. (1969) Thermodynamic equilibria between animals and their environment. Ecol. Monogr. 39, 245-270.

RüBSAMEN K. \& KeTtembell (1980) Effect of water restriction on oxygen uptake, evaporative water loss and body temperature of the rock hyrax. J. comp. Physiol. 138, $315-320$.

Scholander P. F., Walters V., Hock R. \& Irving L. (1950) Heat regulation in some arctic and tropical animals and birds. Biol. Bull. 99, 236-258.

Stones R. C. \& Wiebers J. E. (1965) A review of temperature regulation in bats (Chiroptera). Am. Midl. Nat. 74, 155-167.

STRUNK T. H. (1971) Heat loss from a Newtonian animal. $J$. theoret. Biol. 33, 35-61.

Strunk T. H., Tracy C. R. \& Kleiber M. (1973) Technical comments: perspectives of linear heat transfer. Science $181,184186$. 
Studier E. H. \& O'Farrell M. J. (1972) Biology of Myotis thysanodes and M. lucifugus (Chiroptera: Vespertilionidae) - I. Thermoregulation. Comp. Biochem. Physiol. 41A, 567-596.

Studier E. H. \& O'FARrell M. J. (1976) Biology of $M$ votis thysanodes and $M$. lucifugus (Chiroptera: Vespertilionidae)-III. Metabolism, heart rate, breathing rate, evaporative water loss, and general energetics. Comp. Biochem. Physiol. 54A, 423 432 .

Studier E. H., Dapson R. W. \& Bigklow R. E. (1975)
Analysis of polynomial functions for determining maximum or minimum conditions in biological systems. Comp. Biochem. Physiol. 52A, 19-20.

TRACY C. R. (1972) Newton's Law: its applicability for expressing heat losses from homeotherms. Bioscience 22, 656-659.

TUCKeR V. A. (1965) Oxygen consumption, thermal conductance, and torpor in the California pocket mouse Perognathus californicus. J. Cell. comp. Physiol. 65, 393-404. 